\title{
Transperineal approach to complex rectourinary fistulae
}

\author{
Henry Tran, MD; Ryan Flannigan, MD; Daniel Rapoport, MD \\ University of British Columbia, Vancouver, BC, Canada
}

Cite as: Can Urol Assoc J 2015;9(11-12):E916-20. http://dx.doi.org/10.5489/cuaj.3107 Published online December 14, 2015.

\section{Abstract}

Introduction: We sought to present our experience and outcomes in patients with complex rectourethral fistulae (RUF) treated using the transperineal approach with gracilis muscle flap interposition. Complex RUF was defined as having prior radiation, failed repair attempts, and large size $(>2 \mathrm{~cm})$.

Methods: A retrospective review identified 10 patients presenting with complex RUF between July 2009 and November 2013. Three were excluded due to large fistula defects managed with urinary diversion. Seven patients met inclusion criteria and underwent reconstruction.

Results: Six of 7 patients had prostate cancer, and one patient had colon cancer treated with low anterior resection with adjuvant radiation. The primary modality of prostate cancer therapy was brachytherapy $(n=3)$, external beam radiotherapy $(n=2)$ and radical retropubic prostatectomy (RRP) $(n=1)$. Three patients had salvage cancer therapy, including RRP $(n=1)$, cystoprostatectomy with ileal conduit $(n=1)$, and cryotherapy $(n=1)$. One patient developed RUF post-primary RRP without radiation. Mean fistula size was $2.8 \mathrm{~cm}$ $(2-4 \mathrm{~cm})$. No fistulas recurred at mean follow-up 11.4 months (6-20 months). Three patients have had colostomy reversal, one is pending reversal and three have permanent colostomies. Five patients have stress urinary incontinence, with two managed with one to four pads per day, one managed with a condom catheter, and two waiting for artificial urinary sphincter (AUS). One patient developed a perineal wound infection and one developed a pulmonary embolus treated medically.

Conclusion: Complex RUF defects are effectively treated with transperineal repair using gracilis muscle interposition. The procedure has low morbidity and high success. Concomitant stress incontinence and bladder outlet contracture are prevalent in this population and may require ongoing management.

\section{Introduction}

RUF is an uncommon and challenging condition to manage. Fistula formation can be due to inflammation, radia- tion to the pelvis, previous surgery, trauma, or even congenital defects. ${ }^{1-4}$ We defined complex RUF as those having prior radiation, failed repair attempts, and large size $(>2$ $\mathrm{cm})$. A number of RUF have been reported in patients with prostate cancer following radiation and surgical treatment. External beam radiation and brachytherapy are commonly used treatment modalities for select patients with localized prostate cancer. Although rare, the incidence of RUF postbrachytherapy is $0.3-3 \%$, and post-electron beam radiation therapy (EBRT) is $0-0.6 \% .^{5-11}$

The management of RUF is highly variable. Spontaneous closure can occur for small RUF following urinary and fecal diversion, but most require operative intervention. Different surgical approaches described include transanal, transsphincteric, and transabdominal; however, there is no general consensus regarding optimal treatment. ${ }^{12}$ We present our local case series of patients presenting with complex RUF treated using the transperineal approach with gracilis muscle flap interposition.

\section{Methods}

We performed a retrospective review of all patients referred to a single surgeon with complex RUF between July 2009 and November 2013. Fistula etiology, presenting signs and symptoms, preoperative consultations, repair technique results, and followup were obtained from the electronic medical records for each patient. Ten patients presenting with complex RUF were identified, but three were excluded due to very large fistula size and were managed with urinary diversion alone. The remaining seven patients underwent reconstruction. Each patient was assessed with manual examination, cystoscopy, and proctoscopy. Evaluation of fistula size, location, urethral and anal sphincter condition, as well as degree of necrosis of adjacent tissues and fistula tract were undertaken and used in preoperative planning. All patients underwent initial fecal diversion and subsequent RUF repair via transperineal approach with gracilis muscle interposition. 


\section{Surgical technique}

With the patient in exaggerated dorsal lithotomy position, cystoscopy is performed and the fistula is identified. A ureteral catheter is inserted through the fistula tract and pulled out of the anus. An inverted $U$ perineal incision is made extending from one ischial tuberosity to the other above the anal sphincter (Fig. 1). The subcutaneous tissue and colles fascia is incised and the ischiorectal fossa is developed. The anal sphincter is preserved. Dissection proceeds along the anterior rectal wall until the fistula is identified and completely mobilized. Lateral dissection is performed with the goal to aid in subsequent tension-free closure of rectum.

The rectum is repaired in two layers taking care to invert the rectal mucosa. Large urethral defects are closed with buccal mucosa graft as needed. Otherwise, the urethral defect is closed with 3-O vicryl interrupted sutures. We perform our own gracilis flap harvest. The left gracilis muscle is preferred and tunneled into the perineum under colles fascia and fascia lata. The apex of the muscle graft is spread fixed to the anterior rectal wall and bladder base beyond the fistula repair. The edges of the gracilis muscle are secured to the superficial perineal fascial layers (Fig. 2). The operative area is closed in standard fashion with a closed suction drain inserted at the left thigh harvest site and a penrose drain in the perineum. Foley and suprapubic catheters are left to drainage. Patients are kept on intravenous antibiotics for 48 hours and usually discharged after two to three days. Voiding cytourethrogram is performed four weeks postoperatively and catheters removed shortly thereafter. Cystoscopy is performed three to six months postoperatively.

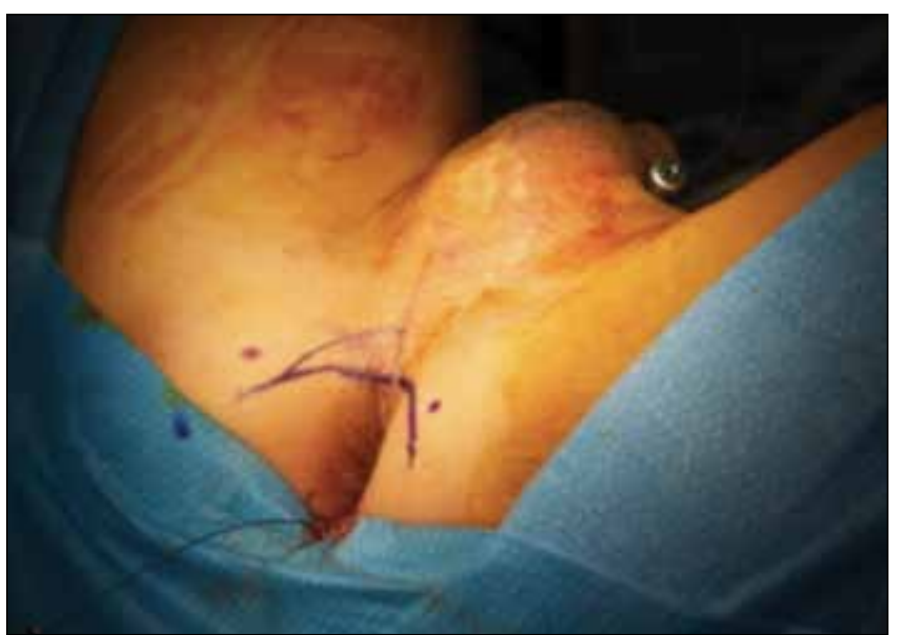

Fig. 1. Inverted U transperineal incision. Ischial tuberosities marked out Provides excellent exposure of rectum and urethra. Further urethral reconstruction using buccal mucosa grafting can be undertaken if needed.

\section{Results}

Seven male patients were identified with a mean age of 69 years (58-84). Six of 7 patients had prostate cancer and one patient had colon cancer treated with low anterior resection and adjuvant radiation. The primary modality of prostate cancer treatment was brachytherapy $(n=3)$, external beam radiotherapy $(n=2)$, and RRP $(n=1)$. Three patients had salvage prostate cancer therapy post -radiation, including radical retropubic prostatectomy $(n=1)$, cystoprostatectomy with ileal conduit $(n=1)$, and cryotherapy $(n=1)$ (Table 1$)$.

Two patients had transurethral resection of outlet contracture following prostate cancer therapy. The patient who underwent primary RRP presented with fecaluria and RUF within the first few days after surgery and did not receive any other adjuvant treatments. Mean fistula size was 2.8 $\mathrm{cm}(2-4 \mathrm{~cm})$. Five of 7 patients had fistula at the membranous urethra, and the remaining two had fistulas at the prostatic urethra (Table 2). Two patients had previous failed attempts at fistula repair via transabdominal and transanal approaches.

Among preoperative considerations, all seven patients received diverting colostomies. Five of seven patients had urinary diversion via foley catheter $(n=1)$, suprapubic catheter $(n=3)$, or ileal conduit $(n=1)$. Two patients had received hyperbaric oxygen preoperatively. Mean operative time, including gracilis flap harvest was 170 mins (147-253 mins). None of the patients required any blood transfusions, with an average estimated blood loss of $260 \mathrm{~mL}$ in five of seven patients $(100-500 \mathrm{~mL})$. Average length of stay in hospital was 3.6 days ( $2-8$ days).

After fistula repair, five patients had an uncomplicated perioperative course; however, one patient developed a wound infection successfully treated with cephalexin and a second patient developed a pulmonary embolism postoperatively, as well as a perineal infection treated with cefixime and metronidazole (Table 3).

The outcomes of these patients have been positive. There have been no fistula recurrences at mean followup 11.4 months (6-20 months). All seven patients have experienced treatment success, defined as resolution of fistula symptoms and radiographic and endoscopic resolution of the fistula itself. Three patients have had colostomy reversal, three have permanent colostomies, and one is pending reversal. Five patients have stress urinary incontinence. Two patients are managed with one to four pads per day, one patient is managed with a condom catheter, and two patients are pending artificial urinary sphincter insertion (Table 4). Notably, there was no particular long-term morbidity or complication related to gracilis muscle harvest. 
Tran et al.

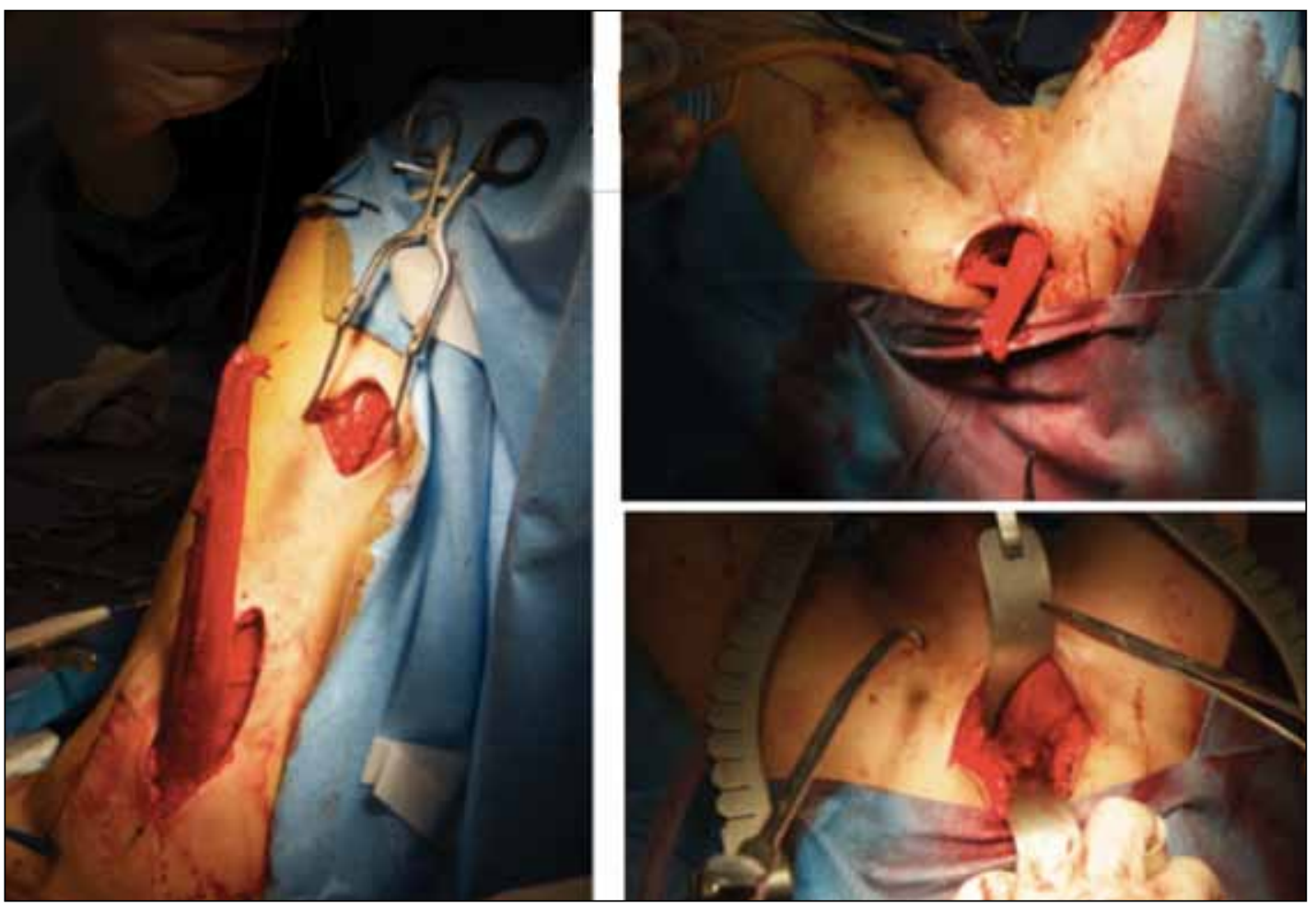

Fig. 2. Left gracilis muscle harvest. Adequate vascular supply must be maintained with the graft. Subsequent tunneling of released graft into perineum. Gracilis muscle edges are approximated to superficial perineal fascial layers.

\section{Discussion}

The treatment goal for RUF, although not always possible, should be fistula closure and restoration of bowel and bladder function. Each patient presenting with RUF should be managed individually based on fistula etiology, pre-existing comorbidities and life expectancy, and baseline urinary and bowel function. Six of seven patients in our series had a history of pelvic radiation exposure. With the increasing use of external beam radiation and brachytherapy in management of localized prostate cancer, radiation-induced rectourethral fistulas have become a significant clinical problem. Radiation causes damage to pelvic microvasculature, stro- mal fibrosis, and formation of ulcers and mucosal erosions. The poor vasculature and damaged tissues also increase risk of fistula recurrence. Recent studies suggest up to $50 \%$ of patients with RUF have a history of pelvic radiation. ${ }^{13}$

Treatment of fistulas depends on their severity and location. Typically, initial fecal diversion and urinary drainage (suprapubic or foley catheter) is undertaken, which decreases inflammation and risk of sepsis in the area. ${ }^{13,14}$ Afterwards, subsequent primary fistula closure is undertaken. Up to $25 \%$ of simple RUF can heal spontaneously with these conservative measures, but for post-radiation fistulas, this is unlikely. ${ }^{14,15}$ In our series, all patients underwent initial diverting colostomy. Five of seven patients had preopera-

Table 1. Primary cancer diagnosis and subsequent treatments

\begin{tabular}{|c|c|c|c|c|}
\hline Patient & Age & $\begin{array}{l}\text { Most responsible } \\
\text { diagnosis }\end{array}$ & Primary treatment modality & Subsequent treatments \\
\hline 1 & 70 & Prostate cancer & Radiation, EBRT + ADT & Salvage RRP \\
\hline 2 & 64 & Prostate cancer & RRP & None \\
\hline 3 & 69 & Prostate cancer & Brachytherapy & TURBN for BNC \\
\hline 4 & 68 & Prostate cancer & Brachytherapy & $\begin{array}{l}\text { Salvage cystoprostatectomy + ileal conduit; transabdominal } \\
\text { RUF repair attempt; transanal RUF repair attempt }\end{array}$ \\
\hline 5 & 84 & Prostate cancer & Brachytherapy & Salvage cryotherapy; TURP for obstructive LUTS \\
\hline 6 & 69 & Prostate cancer & Brachytherapy & None \\
\hline 7 & 58 & Colon cancer & $\begin{array}{l}\text { Low anterior resection }+ \\
\text { adjuvant radiation, EBRT }\end{array}$ & \\
\hline
\end{tabular}

ADT: Androgen-deprivation therapy; BNC: bladder neck contracture; EBRT: electron beam radiation therapy ; LUTS: lower urinary tract symptoms; RRP: radical retropubic prostatectomy; TURBN: transurethral resection of the bladder neck; TURP: transurethral resection of the prostate. 


\begin{tabular}{lccccc}
\hline \multicolumn{4}{l}{ Table 2. Fistula characteristics } & & \\
\hline Patient & Fistula length & Fistula location & Prior fistula repair attempt & Preoperative urinary diversion & Preoperative colostomy \\
\hline 1 & $3 \mathrm{~cm}$ & Bladder neck & No & Urethral foley & Yes \\
2 & $2 \mathrm{~cm}$ & Membranous urethra & No & None & Yes \\
3 & N/A & Prostatic urethra & No & Ileal conduit & Yes \\
4 & $3 \mathrm{~cm}$ & Membranous urethra & Yes & SP & Yes \\
5 & $4 \mathrm{~cm}$ & Bladder neck & No & SP & None \\
6 & $3 \mathrm{~cm}$ & Membranous urethra & No & Yes \\
\hline
\end{tabular}

tive urinary drainage in the form of suprapubic $(n=3)$, foley catheter $(n=1)$, or ileal conduit $(n=1)$.

Various approaches exist for surgical repair of fistula. The transanal approach with rectal advancement flap can be used for small fistula close to the anus. It causes less postoperative pain and allows further procedures to be done, if required. Unfortunately, it has very limited exposure and access to the urinary tract and is reserved for small, lowlying fistulas. It is typically avoided in situations with prior radiation exposure.

Transsphincteric approaches, such as the York-Mason method have been described and widely used. ${ }^{16}$ Preservation of potency, urinary continence, and rectal innervation is possible because the lateral pelvic and pararectal space is avoided. However, exposure of the bulbar and membranous urethra is difficult. Also, there is a recognized problem with fecal incontinence and, therefore, the procedure should be avoided in those with severe radiation proctitis. ${ }^{12}$ The transsphincteric approach cannot be used for large, complex fistulas due to limited exposure. ${ }^{15}$

The transabdominal approach is rarely used due to the deep pelvic dissection required, although it has been used in some patients with severe radiation damage requiring extensive resection and permanent diversions.

The most commonly used method for RUF repair is the transperineal approach. It allows for wide exposure of the rectum and urethra. Urethral reconstruction, , including buccal mucosal grafting, can be performed easily with this approach. ${ }^{13}$ A number of tissue interposition options exist, such as gracilis, dartos, gluteus maximus, omentum, island groin, scrotal myocutaneous, and dartos pedicle flaps. All patients in our series underwent transperineal repair with gracilis muscle interposition flaps for fistula ranging from 2-4 cm in length located between the bladder neck and the membranous urethra. The gracilis muscle was selected because it is far from previous radiation fields, has excellent vascularity, and is easily mobilized with minimal donor site morbidity. ${ }^{17-19}$

In our series, mean followup at 11.4 months (3-20 months) showed no evidence of fistula recurrence in any patients. The two patients who had prior failed attempts at fistula repair also have not had any fistula recurrence at three and 14 months' followup, respectively. All patients underwent primary closure of the urethral defect. Hence, the transperineal technique appears feasible even in patients who have had prior failed repair attempts. Excellent success rates have also been reported in the literature in patients requiring use of buccal mucosal graft urethral closure. ${ }^{13}$

Stress urinary incontinence was seen in $70 \%$ of our patients. Other series have reported stress incontinence rates of $58 \%$ following transperineal with gracilis muscle interposition repair. ${ }^{20}$ In that series, only $15 \%$ of the patients felt that the incontinence had a significant impact on their quality of life. Similarly, only $28 \%(2 / 7)$ of our patients are severely symptomatic and are currently awaiting placement of an artificial urethral sphincter, with the remainder being content with wearing one to four pads per day.

\begin{tabular}{|c|c|c|c|c|c|}
\hline Patient & $\begin{array}{l}\text { OR time } \\
\text { (mins) }\end{array}$ & $\begin{array}{l}\text { Estimated blood } \\
\text { loss }(\mathrm{mL})\end{array}$ & $\begin{array}{l}\text { Length of stay in } \\
\text { hospital }\end{array}$ & Complications & Complication treatment \\
\hline 1 & 253 & 500 & 3 & None & $\mathrm{N} / \mathrm{A}$ \\
\hline 2 & 158 & 300 & 5 & Wound + perineal infection & Keflex \\
\hline 3 & 157 & $\mathrm{~N} / \mathrm{A}$ & 8 & None & $\mathrm{N} / \mathrm{A}$ \\
\hline 4 & 151 & 300 & 2 & None & N/A \\
\hline 5 & 147 & 100 & 2 & None & $\mathrm{N} / \mathrm{A}$ \\
\hline 6 & 165 & $\mathrm{~N} / \mathrm{A}$ & 2 & $\mathrm{PE}$, perineal infection & Anticoagulation Suprax + Flagyl \\
\hline 7 & 156 & 100 & 2 & None & $\mathrm{N} / \mathrm{A}$ \\
\hline
\end{tabular}


Tran et al.

\begin{tabular}{lccccc}
\hline Table 4. Postoperative outcomes & & & \\
\hline Patient & $\begin{array}{c}\text { Followup period } \\
\text { (months) }\end{array}$ & $\begin{array}{c}\text { Fistula } \\
\text { recurrence? }\end{array}$ & $\begin{array}{c}\text { Bladder neck } \\
\text { contracture }\end{array}$ & Stress incontinence? & Incontinence management \\
\hline 1 & 6 & No & Yes & Yes & Pending AUS \\
2 & 13 & No & Yes & Yes & Pending AUS \\
3 & 12 & No & Yes & No & N/A \\
4 & 3 & No & No & Yes & Condom catheter \\
5 & 20 & No & No & Yes & No \\
6 & 12 & No & No & Nod/day & N/A \\
7
\end{tabular}

AUS: artificial urinary sphincter.

\section{Conclusion}

Complex RUF can be closed successfully using a transperineal approach with gracilis muscle interposition. Adequate bowel and bladder function is preserved, with minimal morbidity. Although none of our patients required it, buccal mucosa grafting can be used to reconstruct severe urethral defects as well. Despite urinary incontinence being a common problem in these patients, overall satisfaction is high compared to before surgical reconstruction. This approach has proven to be robust even in patients with prior failed attempts at fistula repair, and we will continue to use it for patients presenting with complex RUF.

Competing interests: The authors declare no competing financial or personal interests.

This paper has been peer-reviewed.

\section{References}

1. Bukowski TP, Chakrabarty A, Powell IJ, et al. Acquired rectourethral fistula: Methods of repair. J Urol 1995; 153:730-3. http://dx.doi.org/10.1016/S0022-5347(01)67701-2

2. Moss RL, Ryan JA. Management of enterovesical fistula. Am J Surg 1990; 159:514-7. http://dx.doi. org/10.1016/S0002-9610(05)81259-0

3. Munoz M, Nelson H, Harrington J. Management of acquired rectourinary fistulas: Outcome according to the cause. Dis Col Rec 1998; 41:1230-8. http://dx.doi.org/10.1007/BF02258219

4. Izawa JI, Ajam K, McGuire E, et al. Major surgery to manage definitively severe complications of salvage cryotherapy for prostatic cancer. J Urol 2000; 164:1978-81. http://dx.doi.org/10.1016/S0022. $5347(05) 66932-7$

5. Chrouser KL, Leibovich BC, Sweat SD, et al. Urinary fistulas following external radiation or permanent brachytherapy for the treatment of prostate cancer. J Urol 2005; 173:1953-7. http://dx.doi. org/10.1097/01.ju.0000158041.77063.ff
6. Stone NN, Stock RG. Complications following permanent prostate brachytherapy. Eur Urol 2002; 41:42733. http://dx.doi.org/10.1016/S0302-2838(02)00019-2

7. Hu K, Wallner K. Clinical course of rectal bleeding following l-125 prostate brachytherapy. Int I Radiat Oncol Biol Phys 1998; 41:263-5. http://dx.doi.org/10.1016/S0360-3016(98)00080-7

8. Wallner K, Roy J, Harrison L. Tumour control and morbidity following transperineal iodine 125 implantation for stage T1/T2 prostatic carcinoma. J Clin Oncol 1996; 14:449-53.

9. Theodorescu D, Gillenwater JY, Koutrouvelis PG. Prostatourethral-rectal fistula after prostate brachytherapy. Cancer 2000; 89:2085-91. http://dx.doi.org/10.1002/1097-0142(20001115)89:10<2085::AlDCNCR8 $>3.0 .00 ; 2-0$

10. Huang EH, Pollack A, Levy L, et al. Late rectal toxicity: Dose-volume effects of conformal radiotherapy for prostate cancer. Int J Radiat Oncol Biol Physics 2002; 54:1314-21. http://dx.doi.org/10.1016/ S0360-3016(02)03742-2

11. Pisansky TM, Kozelsky TF, Myers RP, et al. Radiotherapy for isolated serum prostate specific antigen elevation after prostatectomy for prostate cancer. J Urol 2000; 163:845-50. http://dx.doi.org/10.1016/ S0022-5347(05)67817-2

12. Choi JH, Jeon BG, Choi $S$, et al. Rectourethral fistula: A systematic review of and experiences with various surgical treatment methods. Ann Coloproctol 2014; 30:35-41. http://dx.doi.org/10.3393/ ac.2014.30.1.35

13. Lane BR, Stein DE, Remzi FH, et al. Management of radiotherapy induced rectourethral fistula. J Urol 2006; 175:1382-88. http://dx.doi.org/10.1016/S0022-5347(05)00687-7

14. Visser BC, McAninch JW, Welton ML. Rectourethral fistulae: The perineal approach. J Am Coll Surg 2002; 195:138-43. http://dx.doi.org/10.1016/S1072-7515(02)01207-3

15. Gupta G, Kumar S, Kekre NS, et al. Surgical management of rectourethral fistula. J Urol 2008; 71:267-71. http://dx.doi.org/10.1016/j.urology.2007.10.042

16. Renshler TD, Middlegton RG. 30 years' experience with York-Mason repair of rectourinary fistulas. J Urol 2003; 170:1222-5. http://dx.doi.org/10.1097/01.ju.0000082013.58783.17

17. Wexner SD, Ruiz DE, Genua J, et al. Gracilis muscle interposition for the treatment of rectourethral, rectovaginal, and pouch-vaginal fistulas: Results in 53 patients. Ann Surg 2008; 248:39-43. http:// dx.doi.org/10.1097/SLA.0b013e31817d077d

18. Zinman L. Managing complex rectourethral fistulas. Contemp Urol 2005; 30-40.

19. Ryan JA, Beebe HG, Gibbons RP. Gracilis muscle flap for the persistent perineal sinus of inflammatory bowel disease. Am J Surg 1979; 122:124-5.

20. Samplaski MK, Wood HM, Lane BR, et al. Functional and quality-of-life outcomes in patients undergoing transperineal repair with gracilis muscle interposition for complex rectourethral fistula. Urology 2011; 77:736-41. http://dx.doi.org/10.1016/i.urology.2010.08.009

Correspondence: Dr. Henry Tran, University of British Columbia, Vancouver, BC, Canada; henryhył@gmail.com 